\title{
El poblado del soberano: memorias de un viaje a la profundidad de sus tradiciones y sus gentes
}

\author{
Ángela Jasmín Fonseca-Reyes*
}

* Licenciada en Ciencias Sociales, Universidad Pedagógica y Tecnológica de Colombia, Tunja, Colombia. Investigadora del Grupo Historia y Prospectiva de la Universidad Latinoamericana y docente de básica y media en el colegio Santo Tomás, Chía, Colombia. Correo electrónico: angelafonrey@gmail.com

Recibido: 30 de abril del 2014 Aprobado: 12 de junio del 2014

Cómo citar este artículo: Fonseca-Reyes, Ángela Jasmín. "El poblado del soberano: memorias de un viaje a la profundidad de sus tradiciones y sus gentes". Rastros Rostros 16.30 (2014): 105-114. Impreso. doi: http:// dx.doi.org/10.16925/ra.v16i30.825

\begin{abstract}
Resumen
Las palabras que conforman este texto nacen como una alternativa para socializar, a manera de relato literario, los resultados del trabajo de investigación "Tradición cultural y didáctica de las ciencias sociales en el municipio de Sotaquirá", que logró fomentar los espacios de reflexión sobre las tradiciones culturales de Sotaquirá, al interior del aula en Institución Educativa Pablo vi y consolidó espacios de aprendizaje significativos, en torno a los saberes ancestrales vigentes en la región. El objetivo de esta investigación fue redescubrir etnográficamente las tradiciones culturales del campesinado del municipio de Sotaquirá, para diseñar propuestas didácticas alternativas aplicables al aula en el campo de las ciencias sociales en secundaria y media del Colegio Pablo vi, mediante un sustancioso y agradable trabajo de campo basado en observación participante, charlas esporádicas, relaciones fraternas, convivencia, entrevistas formales e informales en el marco de una práctica pedagógica en la mencionada institución educativa. Estos fueron elementos fundamentales para comprender y describir la esencia de algunas tradiciones culturales que persisten en gran parte de la comunidad sotaquireña. Finalmente, este trabajo investigativo contribuyó a que los estudiantes valoraran significativamente los elementos que hacen parte de su cultura regional. De igual forma se consiguió fortalecer los vínculos intergeneracionales, lo que demostró la necesidad y la urgencia de la planeación y construcción colectiva de un proyecto educativo comunal paralelo al proyecto educativo institucional.
\end{abstract}

Palabras clave: etnografía, práctica pedagógica, proyecto educativo comunal, tradición cultural.

\section{The Sovereign's Village: Memories of a Profound Journey into its Traditions and Peoples}

\begin{abstract}
This article, written in the style of a literary tale, arose as an alternative for sharing the results of the research study titled "The Cultural and Didactic Tradition of Social Sciences in the Sotaquirá Municipality". This study fomented spaces for reflection on Sotaquirás cultural traditions within the classrooms of the Institución Educativa Pablo vi, and consolidated important spaces for learning around the prevailing ancestral knowledge in the region. The objective of this research study was to ethnographically rediscover the cultural traditions of country dwellers in the Sotaquirá municipality, in order to design alternative proposals for social science teaching in the secondary school classroom of the Colegio Pablo VI. This was achieved through substantial and pleasant fieldwork based on participant observation, occasional conversations, fraternal relationships, coexistence, and formal and informal interviews within a framework of pedagogical practice in the above school. These were the basic elements for understanding and describing the essence of certain cultural traditions that mostly still exist in the community of Sotaquirá. Finally, this research study contributed to the students attaching great value to aspects of their regional culture. Likewise, it strengthened intergenerational ties, showing the pressing need for the collective planning and creation of a communal educational project in parallel to the project conducted in the school.
\end{abstract}

Keywords: ethnography, pedagogical practice, communal educational project, cultural tradition.

\section{O povoado do soberano: memórias de uma viagem à profundidade de suas tradições e sua gente}

\section{Resumo}

As palavras que formam este texto nascem como uma alternativa para socializar, como uma narrativa literária, os resultados do trabalho de pesquisa “Tradição cultural e didática das ciências sociais no município de Sotaquirá", que conseguiu fomentar os espaços de reflexão sobre as tradições culturais de Sotaquirá, dentro da sala de aula na Instituição Educativa Pablo VI e consolidou espaços de aprendizagem significativos, em torno aos saberes ancestrais vigentes na região. O objetivo desta pesquisa foi redescobrir etnograficamente as tradições culturais do campesinato do município de Sotaquirá, para elaborar propostas didáticas alternativas aplicáveis à sala de aula no campo das ciências sociais no ensino médio do Colégio Pablo VI, mediante um substancioso e agradável trabalho de campo baseado na observação participante, conversas esporádicas, relações fraternas, convivência, entrevistas formais e informais no marco de uma prática pedagógica na mencionada instituição educativa. Estes foram elementos fundamentais para compreender e descrever a essência de algumas tradições culturais que persistem em grande parte da comunidade de Sotaquirá. Finalmente, este trabalho de pesquisa contribuiu para que os estudantes valorizem significativamente os elementos que fazem parte de sua cultura regional. Da mesma forma, consegue-se fortalecer os vínculos intergeracionais, o que demonstrou a necessidade e a urgência do planejamento e construção coletiva de um projeto educativo comunal paralelo ao projeto educativo institucional.

Palavras-chave: etnografia, prática pedagógica, projeto educativo comunal, tradição cultural. 


\section{Recorriendo los caminos de los recuerdos}

\author{
Apreciada/o viajera/o:
}

Las rutas y recorridos que se plasman en las siguientes líneas te conducirán a diversos lugares, momentos, sentimientos y percepciones construidos desde los imaginarios y vivencias de la comunidad sotaquireña, narrados a través de las voces ocultas de varios/as ancianos/as y jóvenes, que voluntariamente decidieron participar en el trabajo de investigación "Tradición Cultural y Didáctica de las Ciencias Sociales en el Municipio de Sotaquirá".

Para emprender el viaje, además de una buena porción de curiosidad y fantasía, necesitas echar a volar tu imaginación, elementos fundamentales para comprender el incalculable valor y trascendencia de las permanencias culturales en la comunidad sotaquireña, recreadas por medio de las palabras, emociones, vivencias, subjetividades, anhelos, supersticiones, sueños, narraciones, que varias personas decidieron compartir sobre la cultura campesina, los saberes ancestrales y sus relaciones con el espacio que hicieron posible este sueño tejido colectivamente.

No olvides reservar en tu equipaje espacio para guardar el aroma de los recuerdos y los murmullos del campo amenizados con los relatos de los abuelos y las jugarretas de los/as jovencitos/as, la textura de la tierra y el sabor de los diversos y deliciosos manjares cuyas recetas se darán a conocer al final de la ruta. Estos contienen un alto contenido pedagógico, enfocado a dar a conocer la planeación y ejecución de algunos de los talleres pedagógicos que se aplicaron con en la Institución Educativa Pablo vi en el marco del mencionado proyecto.

Infortunadamente, por falta de tiempo, se darán a probar pequeñas degustaciones, suficientes para aumentar tu curiosidad y abrir tu apetito de conocimiento, preparados con aderezos de palabras y servidos como experiencias, surgidas a partir de entrevistas y conversaciones esporádicas que consolidaron el trabajo etnográfico. Lo anterior repercutió en la manera de percibir y comprender la trascendencia y vigencia de la cultura campesina en dicha comunidad. Por eso, si deseas probar manjares mágicos en medio del viaje, asume el reto de seguir el camino de los recuerdos que conducen al Poblado del Soberano.

\section{El poblado del soberano}

Cualquier hora del día es ideal para emprender este viaje de ensueño, los caminos que conducen a Sotaquirá, que, en lengua chibcha, quiere decir "poblado del soberano" (Rodríguez 54); se despliegan por los paisajes de la inmensa Cordillera Oriental de los Andes boyacenses, el municipio se levanta en medio de mesetas, laderas, valles ondulados y el Siome o Santo Ecceomo, el cerro más elevado de la provincia centro. Antes de emprender el vuelo, es pertinente recordar que la cultura es un constructo colectivo, histórico, político y geográfico que se evidencia constantemente en los comportamientos de las personas de un lugar específico y que han prevalecido vigentes generacionalmente, en palabras de Warnier (14):

Toda cultura es singular, está geográfica o socialmente localizada, es objeto de expresión discursiva de una lengua dada, es factor de identificación para los grupos y los individuos y de diferenciación respecto a los demás, y también es un factor de orientación de los actores en sus relaciones mutuas y en sus relaciones con el ambiente que los rodea. Toda cultura se trasmite a través de las tradiciones reformuladas en función del contexto histórico.

El tiempo en este territorio ha contemplado el caminar de sucesos esplendorosos y devastadores de generaciones de hombres y mujeres, que han construido sus vidas en torno a los medios que la naturaleza ofrece y las dinámicas sociales, políticas y económicas que han moldeado su identidad regional. Según Ocampo (125):

La sociedad boyacense en su dimensión espacial a través del tiempo, se identifica con su conformación étnico-cultural, su historia, su sistema de vigencias, costumbres, tradiciones, usos cotidianos, creencias y su folclor, los cuales ofrecen tipicidad y autenticidad.

A simple vista, se pueden percibir los diversos matices de los verdes que adornan el hermoso valle sotaquireño, sus extensas praderas conforman la zona central del municipio divididas por la vía que comunica la avenida central con el casco urbano del pueblo, durante el trayecto se pueden observar unas esporádicas casas rodeadas de pasto. De la carretera, medianamente ascendente, se desprenden pequeños caminos reales que conducen a las diferentes veredas de esta zona, el vaivén de los carros interrumpe los rumores 
del campo y, a la vez, distraen la vista de don Antonio, quien a sus 84 años contempla el trascurrir de los días sentado frente a su casa con el bastón entre sus manos ya cansadas, su vigorosa voz arrulladora nos trasporta a la realidad de sus memorias y valiéndose de las historias heredadas de sus abuelos nos explica que

aquí a los de Sotaquirá nos dicen los ahumados; como a los de Toca les dicen los matacristos; a los de Tuta trabagaches; a los tunjanos los piojosos; a los de Chiquinquirá, los cuatro manos ... y eso que nos digan a nosotros así, es porque cuentan, la gente dice, que era que había una fábrica de textiles en Tuta, y ahí en el piso ponían esteras desas que hacían o todavía hacen en Avendaños. Resulta que un día se quemó la fábrica y prendió rapidito porque cogió las esteras y eso prende bien porque son de gache y esparto, entonces ahí fue que empezaron a decir que se quemaron los de Sotaquirá y se pasó el humo pa este lado y por eso los de acá son los ahumados.

También se dice que es porque cuando llegaron aquí los españoles hicieron una iglesia y un día cayó un aguacerón bravo y en esas cayó un rayo que prendió el techo de la iglesia, que era de paja, como las demás casas de poray, y se prendió la iglesia y echó a ahumar todo, y así varios techos de las casas de al lado también se prendieron y por eso, nos llaman los ahumados.

Siguiendo los senderos del sector, se pueden contemplar los inmensos pinos, sauces y eucaliptos que bordean la vía, también rodeada de huertos de las pocas casas de adobe y tapia pisada que se encuentran cerca de la carretera. Asimismo, sobresalen las ramas de árboles frutales principalmente: ciruelo, durazno, manzano, en menor medida feijoa, mora y fresa, cultivados tradicionalmente. El cultivo tecnificado se encuentra en descenso debido a los altos costos en la producción, la tecnología que debe emplearse y la competencia internacional impuesta por los tratados de libre comercio; aunado a esto, la contaminación ambiental generada por las industrias establecidas en la región, que perjudican notablemente el buen desarrollo de los frutales. Las gentes del lugar aseveran que la tierra ya está desgastada y cansada.

A cierta distancia del camino puede contemplarse a dos hombres jóvenes apretando un cajón de madera que sostiene un incipiente muro en tapia pisada, como se aprecia en la figura 1, atendiendo las instrucciones de don Luis, su padre. Él melancólicamente comenta:

Uno le brega a sembrar las maticas, así todo con abono y todo y no, ya no dan igual. Anteriormente era pero esas matas que se desgajaban de pepas, ahorita no, igual yo me dedico a ver de mi huerto y a ver de mi agricultura, yo en este trabajo, yo me he amañado, sí, ahí le toca a uno fregar y todo, pero yo me he amañado en este trabajo.

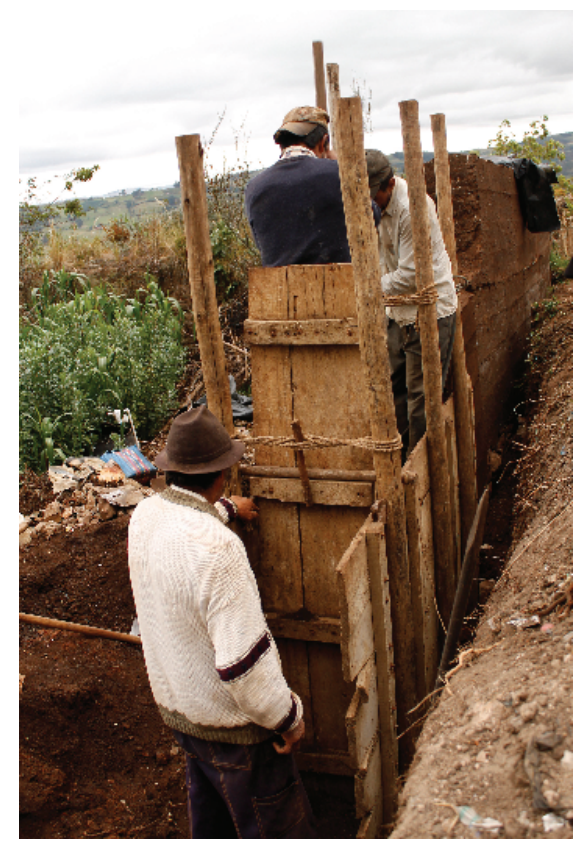

Figura 1. Don Luis y sus hijos.

Fuente: Juan David Corredor Robles, agosto del 2012.

Mientras el sonido del pisón retumba y rompe el silencio en el ambiente, la tierra encajonada se va apretando y la pared de tapia se va levantando. El proceso de construcción es de paciencia e implica varios participantes. A sus 61 años y con 31 de experiencia, don Luis nos comenta que aprendió esta labor de sus mayores y de la misma manera se la trasmitió a sus hijos:

Pues el material que se utiliza para hacer tapia pisada es todo lo más arreglado y puesto bien anivelado, y la piedra, y hay si cuadrar el tapial y aplomarlo bien, y cuadrar la piedra bien, asentarla piedra bien, asentadita, que quede bien firme, que no quede lunanca porque si no se cae, la piedra se cae y enton la pared se viene desbloqueteando y se va a caer la pared, enton es una cerca, que en de que quede bien construida, pues entonces eso va a durar un poco de tiempo, si eso dura bastante tiempo, que eso no hay necesidad de ponerle más gastos.

Retomando el recorrido, es preciso continuar por la desordenada y estrecha carretera que comienza a ascender dejando atrás el valle, las praderas se pierden en la distancia mientras el sol se despide al esconderse detrás de las montañas. Alrededor de la vía empiezan 
a aparecer grandes construcciones que anuncian la llegada al pueblo, unas pocas con aspecto medianamente reciente, otras de estilo muy colonial: hechas de adobe y tapia pisada, parecen suspendidas en el tiempo, deterioradas por los años y el olvido, pintadas de blanco, con grandes ventanas balconadas de marco verde y tejas de barro.

Hemos llegado al pueblo en medio de las tinieblas de la noche, el profundo resplandor de la luna llena termina de opacar a las tenues luces de los bombillos que cuelgan de unos pocos postes; el negro cielo está inmensamente poblado de innumerables estrellitas que juegan a deslizarse en diferentes direcciones acompañando a la luna en su largo desfile nocturno. El frío se apodera por completo del lugar. De una chimenea emergen pequeñas nubecitas de humo cargadas de un tímido olor a fogón casi apagado, que alterna con el fuerte aroma de flores, tierra e insectos, de plantas frutales y aromáticas, en especial, del caballero de la noche.

Mientras la amplia ventana de madera color verde se abre, el recinto oscuro se estremece al recibir los profundos rayos de luz blanca provenientes de la luna, que sin prejuicios exhibe su belleza y grandeza, el viento entra violento penetrando las anchas paredes de adobe que sostienen una más de las tantas casas coloniales que bordean las esquinas de la plaza. En su interior divaga doña Amparito Camargo, una mujer de carácter firme, efusiva, conversadora y amable, quien asegura que nunca ha abandonado Sotaquirá. Esto ha sido por varias razones, principalmente porque, nos dice:

Yo acá estoy, sigo, porque mi abuelita me pegó una maldición, un día me dijo que jamás me iba a poder mover de acá y mire y realmente me amarró acá, yo nunca he podido irme de acá, siempre se me presenta un proyecto u otro tengo la opción de vender, tengo la opción de irme, de iniciar algo nuevo y no puedo, yo en ningún lado me siento feliz, sí, yo en ningún lado soy feliz.

Su alegría y efusividad reflejan el afecto que profesa por esta tierra y sus gentes. Por eso comenta: "Ser campesino no es ser sucio, mal hablado y eso, sino amar a la tierra, estar compenetrado con todos los valores que tiene su región, eso es ser campesino".

Muy cerca de allí, rodeado por una magnífica construcción colonial, adornada con un amplio jardín, se encuentra don Rufino, arrullado por el murmullo del campo y los sonidos de la cocina. A sus 53 años, se caracteriza por ser cordial, amable y solidario, siempre dispuesto a conversar y compartir. Él afirma:
Yo sí quiero mi pueblo, me parece muy bonito, la tranquilidad. Tiene cosas muy bonitas, por lo menos el agua, sin que sea de excelente calidad pero nunca falta, y que no hay tanta contaminación puede salir uno a caminar sin problemas, que a pesar de todo. Pues [que si aprecio a] gente, pues los mayores más que todo, se les pide un favor y están como pendientes de los vecinos, hay como esa camaradería y de que, si [uno] necesita un favor, [dicen] " $i c o n$ mucho gusto!" no se lo niegan. Entonces hay cosas que aún se conservan pero no en la misma intensidad que antes.

Al contemplar las imponentes montañas de la cordillera Oriental, que se levantan vigorosamente rodeando el pueblo, las construcciones coloniales se perciben de mínimo tamaño porque bordean las encumbradas colinas. Los árboles elevan sus largas ramas formando una danza: se balancean empujados por el viento al ritmo de los cantos del campo. En el municipio, las ramas de algunos árboles presos por los muros, se asoman para responder con movimientos la invitación del bosque. En cada tonada despiden inspiradores olores mágicos que se dispersan suavemente, en medio de las grandes casonas, por el gélido ambiente de la madrugada.

La estropeada carretera, cubierta de recebo, está atravesada por una gran zanja, se aleja descendentemente de las deterioradas casas que forman la cuadra periférica del pueblo hacia el sector noroccidental. Gran cantidad de eucaliptos, pinos y sauces adornan el camino y le ponen límites a los pastos que crecen cerca de la carretera, donde algunas vacas rumean acostadas, las flores brillan armoniosas sobre los matorrales de zarza, las plantas de fique extienden sus ramas para sobrepasar las oxidadas cuerdas de alambre de púas y los fragmentados muros desgastados de antiguas cercas hechas de tapia pisada, elementos del camino que insisten en mantenerse en pie.

El canto de los pájaros encaramados sobre las altas ramas de los árboles es como un conjunto de agudas risas contagiosas. Desde el lugar alcanza a percibirse el sonido generado por la corriente del río chocando con las protuberantes rocas que sobresalen en su pequeño y tranquilo cause; llaman la atención las huertas ubicadas en la parte posterior de las casas del pueblo llenas de plantas aromáticas, flores ornamentales, papayuelos, ciruelos, maíz, etc., adornando las bellas montañas sotaquireñas, así como se destacan en la figura 2. 


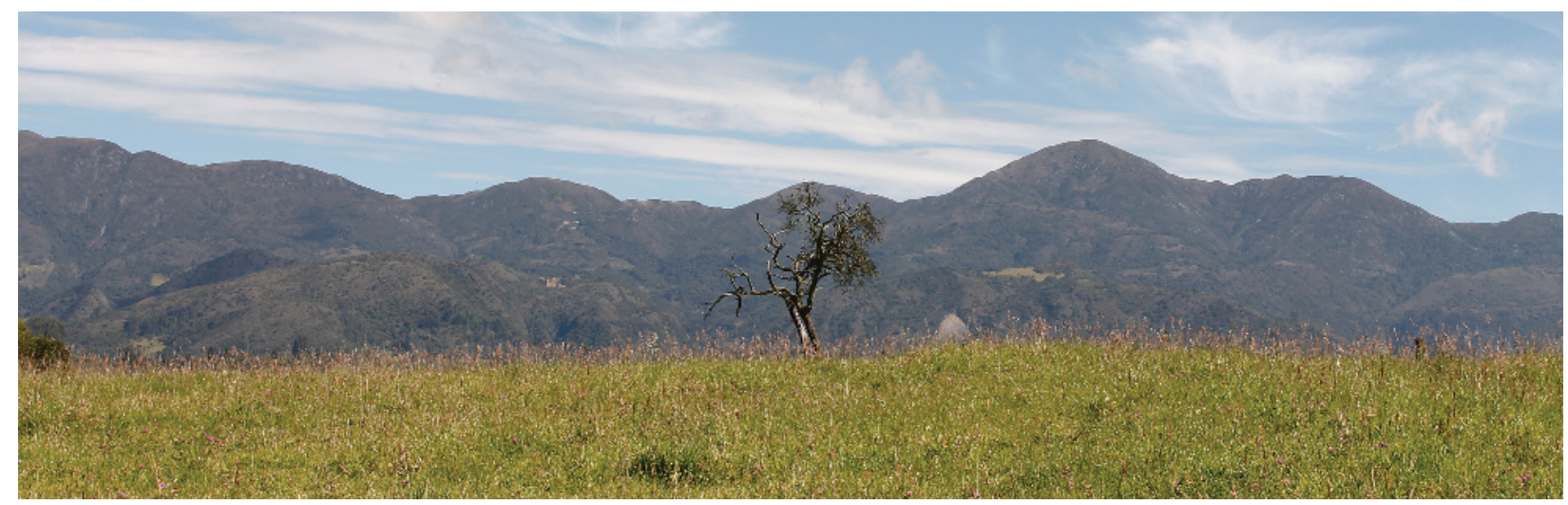

Figura 2. Montañas de Sotaquirá.

Fuente: Juan David Corredor Robles, julio del 2012.

Desviando por un camino real muy empinado, empiezan a verse casitas, unidas por sus huertos. La estrecha carretera se pierde entre las zanjas. A la distancia se ve a doña Jacinta tejiendo una estera con esparto. A su alrededor, sus cinco nietos le colaboran en su ardua labor. Mientras tanto, don Fernando, su esposo, labra la tierra. La mayoría de habitantes de este sector proviene de la vereda Avendaños, la más grande del municipio. Esta carece de vías de acceso e infraestructura, acueducto, alcantarillado y fluido eléctrico, pero cuenta con importantes yacimientos hídricos y prominentes zonas de páramo.

Debido a su edad y las necesidades económicas, ahora residen aquí, en el pie de la montaña a la que siguen adheridos con cuerpo y alma. Sus relatos, cargados de magia, nos transportan a las lagunas (véase figura 3) que se esconden en medio de las montañas; ambos cuentan:

La laguna negra sí queda en lo plano, y a esa le mandan la pedrada y eso se suelta de una el lapo de agua que es rancia, porque de adentro es que salen las nubes y de una llueve. Es en puro momento y es allá dónde se escampa. Una vez le dije al finao Julio: no vaya a hacer el tiro aquí porque estamos puro en frente de la laguna y seguro que nos lavamos. Ese no me creyó, fue y le disparó a unos pajarillos que habían por ahí, dimos como que... andamos por ahí unos cinco minutos y se desploma ese lapo de agua, no me quedó nada seco, esa es brava porque tiene oro.

Apreciado/a lector/a, como te das cuenta, este recorrido ha estado cargado de percepciones y descripciones subjetivas de algunas personas que, con sus voces y relatos, nos han dado a conocer el lugar donde viven y cómo este ha influido en sus formas de ver el

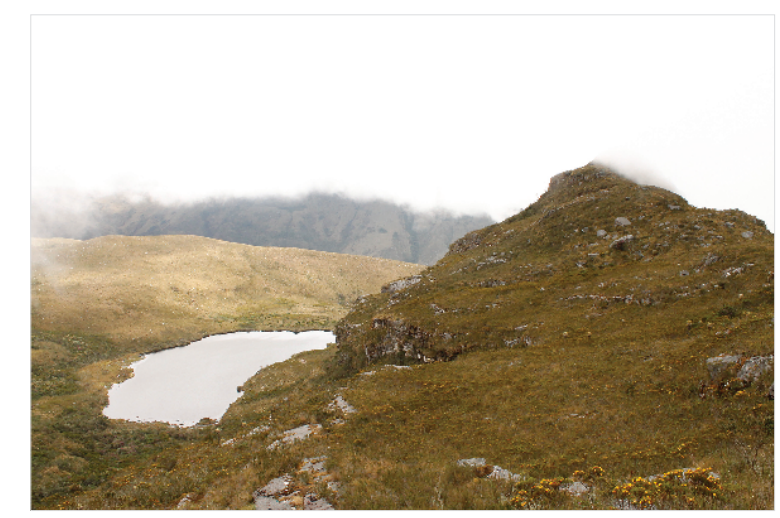

Figura 3. Laguna Negra, Sotaquirá.

Fuente: Juan David Corredor Robles, diciembre del 2012.

mundo y en sus oficios cotidianos. Ahora, la ruta continúa por los senderos de las palabras de personas que esporádicamente quisieron compartir sus relatos, todos relacionados con los mitos o leyendas del pueblo. Antes de continuar, es preciso aclarar que en la sociedad sotaquireña persisten gran cantidad de relatos y leyendas populares, relacionadas con encantos y guacas que surgen de los bosques, montañas y lagunas, historias relacionadas con espantos que merodean y castigan a los desobedientes o a los avaros, lo que confirma las apreciaciones de Ocampo (82):

Los campesinos boyacenses respetan profundamente los lagos, las montañas y las rocas; ninguno habla de nadar en dichos lagos, y ni siquiera de lavar allí sus ropas. Consideran que los "espíritus" o los "encantos" están vinculados a los fenómenos físicos, los ríos, las montañas y las lagunas; inclusive cuando pasan cerca de ésta, hacen la señal de la cruz.

En la vereda de Bosigas Norte, mientras caía un torrencial aguacero, doña María comentaba que en la 
región existían aún muchas guacas, debajo de las haciendas aledañas, que se manifestaban de diferentes maneras:

Eso "puaquí" cuando llueve así fuerte, así como hoy con truenos y todo se ve cómo bajan las guacas y arrastran todo por donde pasaron. Se llevan pedazos grandes de tierra y barro con árboles y piedras, y uno ve cómo brilla el muñeco de oro. Cuando yo era niña, como de seis añitos, estaba jugando en el campo y oí a una niña llorar, estaba detrás de un árbol y era así bien, bien bonita, tenía como una cobija, no me acuerdo bien y me decía que me fuera con ella. Entonces, yo le dije a mi mamá: mire, mire esa niña tan bonita, pero ella no la veía, entonces me regañó y me echó pa la casa.

En la región de Avendaños, popularmente se comenta que, por los ríos Valle y Avendaños, bajan muñequitos de oro, algunos cubiertos con esmeraldas. Durante las fiestas patronales de 2011, varias personas que asistían a la celebración coincidieron en que conocidos suyos habían visto animalitos de oro. La señora Concha habló con nosotros al respecto y nos comentó:

"Puaquí" cuenta la gente que cuando el río viene creci-
do después de que pasa el aguacero se ve cómo brillan
en el agua animalitos o muñequitos de oro, o cuando el
río baja con tierra negra eso dicen que es oro, pero eso
no todo el mundo lo ve. Otros "puay" dicen que arriba
en los pozos negros, puel lado de las lagunas, allá dicen
que se aparecen animalitos blancos, que, cuando uno
los ve, es porque cerca está el oro o las esmeraldas o
que, cuando uno va caminando y se ven que brillan los
cerros como si fueran espejos, es que "puay" cerca debe
de haber diamantes. Otros dicen, a veces, se le puede
presentar a uno un cristo de oro lleno de esmeraldas ahí
en el agua que se ve cerca. Quienes se tiran a cogerlo que
se hunden porque no se deja alcanzar, pero que dizque
hay algunos que si alcanzan a coger algo que apenas
lo agarran se suelta el lapo de agua que no los deja ir
y lo que tienen que hacer es devolver al agua lo que se
encontraron para que se puedan ir.

Como lo podrás notar, durante este recorrido nos hemos internado en las profundidades de los caminos vivos que materializan las percepciones sobre el espacio y la cultura sotaquireña, a través de los ojos y palabras de quienes habitan en ese lugar. Los relatos anteriormente descritos nos permiten, no sólo viajar con la imaginación a este municipio, también nos trasportan al espacio de los afectos y recuerdos de los ancianos que emotivamente quisieron compartirlos con nosotros. Por lo tanto, apreciado/a viajero/a, hemos superado la primera etapa de la ruta. Espero que aparte de recrear bellos pasajes y paisajes, las experiencias y vivencias contadas desde las voces de los abuelos, hayan generado en ti una nueva forma de percibir las tradiciones culturales de la región o sean un pretexto para redescubrirlas por medio del fortalecimiento de las relaciones con la gente mayor que te rodea. De acuerdo con Buenaventura (25): "Hablar por hablar es un juego. Es el más noble y generoso de los juegos humanos y por eso el más socorrido con el don de la risa. Allí el lenguaje es desnudo, no tiene objeto es pura comunicación".

Finalizado el primer tramo, es preciso que sepas que la parte inicial de este viaje fue confeccionado a partir las vivencias de algunos abuelos sotaquireños que decidieron compartirlas con nosotros por medio de algunas entrevistas formales, charlas esporádicas y encuentros casuales, que, además de otorgarnos gratos espacios de conversación y aportarnos sabios conocimientos ancestrales, sirvieron como base teórico-práctica para estructurar, planear y ejecutar once talleres educativos: seis horizontales y cinco verticales, según la clasificación de Ezequiel Ander-Egg (el taller 3). Estos fueron realizados durante la práctica educativa en la Institución Educativa Pablo vi con sede en Sotaquirá.

Esto se hizo con el fin de realizar propuestas pedagógicas alternativas en la escuela para reconfigurar los procesos de enseñanza-aprendizaje de forma consciente, crítica, autónoma y liberadora. De esta forma, se buscaban generar herramientas tangibles para que el estudiantado lograra asumir su realidad desde sus subjetividades y la interrelación formativa de carácter ancestral ligada a su cultura y la educación forjada al interior del aula de clase. En palabras de Pérez y Sánchez (4): "La vida se constituye en el escenario para aprender a resolver, en cada día, la diversidad de dificultades que se presentan. La experiencia de lo colectivo es un vínculo intersubjetivo que se transforma en fuerza para pensar la realidad".

De igual forma, este proceso contribuyó a que los estudiantes de la Institución Educativa Pablo vi, que hicieron parte del proyecto, repensaran el valor cultural de las tradiciones de su región, principalmente mediante el acercamiento y reconocimiento de los relatos de sus abuelos o personas mayores cercanas. No se debe olvidar que, en palabras de Freire (35):

La identidad cultural no puede pretender agotar la totalidad del significado del fenómeno cuyo concepto es la identidad. El atributo cultural acrecentado por el restrictivo de clase no agota la comprensión del término identidad. En el fondo, mujeres y hombres nos hacemos seres especiales y singulares. 
Por esta razón, es fundamental que el ejercicio pedagógico se proyecte al fortalecimiento de relaciones basadas en el respeto a la diversidad y reconocimiento de lo propio, en aspectos individuales y colectivos, en palabras de Freire, "no somos sólo lo que heredamos ni únicamente lo que adquirimos, sino la relación dinámica y procesal de lo que heredamos y lo que adquirimos".

De esta manera, en las próximas líneas, podrás saborear algunos de los manjares que elaboramos colectiva y artesanalmente buscando establecer rutas de comunicación entre la realidad social sotaquireña, su cultura y la educación formal de la institución educativa. Debido al recorrido y el tiempo disponible de este viaje, te presentaré tres experiencias pedagógicas a modo de recetas, también, algunas experiencias obtenidas mediante este hermoso trabajo. Espero que de la misma manera que me sucede, a ti también te llene de alegría, creatividad y deseos preparar tan gratificantes y sabrosos platos de conocimiento.

\section{Recetario pedagógico}

\section{Contacto con la tierra por medio de los sentidos}

\section{Ingredientes}

- 1 libra de tierra negra

- 1 libra de tierra amarilla

- 1 libra de tierra arcillosa

- 1 libra de tierra húmeda

- Una mesa amplia

- Una venda para ojos

- Excesivas cantidades de creatividad

- Todos los sentidos (oído, tacto, olfato, vista y gusto)

Porciones: en este caso, cantidad suficiente para los 28 estudiantes del grado 902.

\section{Forma de prepararse}

Este plato es ideal para propiciar en los comensales, en este caso los estudiantes del grado 902, herramientas de análisis sobre la importancia que posee la tierra dentro de la población campesina, de una manera innovadora y creativa para articular las percepciones sobre la tierra como componente físico-geográfico $\mathrm{y}$, a la vez, como elemento vinculante entre la vida y la cultura.

Para empezar, es imperioso contar con un ambiente de confianza y disposición, ya que la esencia del pla- to radica en que los participantes puedan desenvolverse de forma amena, abiertos al diálogo y libremente para que ellos/as asuman autónomamente la importancia de la tierra para las comunidades rurales como la sotaquireña. Esto contribuirá a que se fomente un proceso de concienciación frente al arraigo de las tradiciones culturales de su terruño a través de los sentidos. Con estos aderezos listos, es preciso disponer en medio del recinto la mesa amplia y sobre esta colocar todos los tipos de tierra. En este punto, se les comenta a los participantes que se deben organizar por grupos para acercarse a la mesa e interactuar con sus sentidos y los distintos tipos de tierra, es decir, la observarán, la tocarán, la olerán, y, si alguno desea, la probará. Finalmente, cada cual le otorgará un sonido característico, denotando las diferencias y semejanzas de cada tipo de tierra, como se ve en la figura 4.

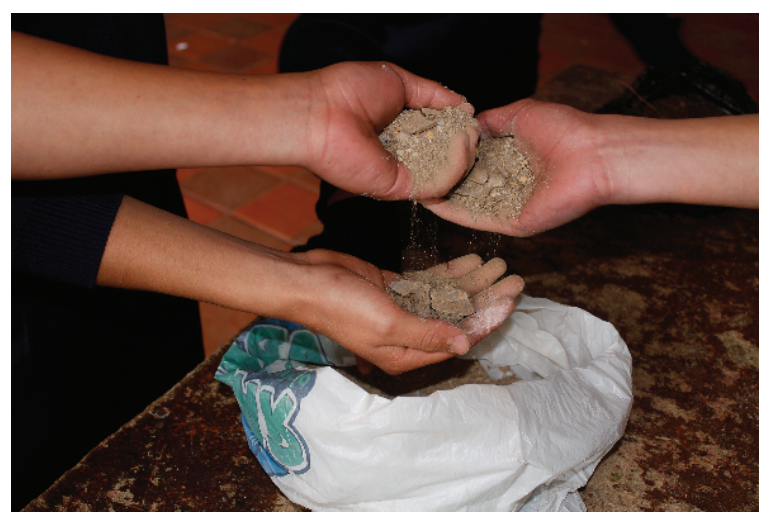

Figura 4. Las manos prestadas.

Fuente: Juan David Corredor Robles.

Al finalizar ese ejercicio, los participantes volverán a interactuar con las distintas tierras, pero esta vez con los ojos vendados. En este momento, cada cual tratará de reconocer cada tipo de tierra. En este punto, se les insta a reflexionar sobre el valor de la tierra no solo como espacio habitable sino como dadora de vida, alimento y refugio para las comunidades rurales. Finalizado el proceso, ya nos podemos deleitar con las delicias que hemos preparado.

\section{Resultados}

Este ejercicio nos llevó a conocer las percepciones y habilidades de los estudiantes, que se decidieron a participar sin prevenciones ni timidez dejando volar su imaginación. Todos los estudiantes acertaron al elegir cada tipo de tierra con los ojos vendados. Al finalizar 
la actividad práctica, se generó un espacio de reflexión en torno a la importancia de la tierra no sólo como elemento fundamental para la vida, sino como medio vivo, dador de existencia y sustento para las comunidades campesinas.

Por otro lado, la actividad rompió la rutina de la academia. Al momento de la socialización, se escucharon voces de satisfacción, debido al ambiente amistoso que causo la actividad. Como conclusión, los estudiantes se mostraron de acuerdo con la importancia de la tierra para el ser humano. A su vez, identificaron al campesino como un constante trabajador, cuidador y conocedor de la tierra.

Esta experiencia contribuyó a que los estudiantes fortalecieran sus habilidades comunicativas. También, constituyó una herramienta para que, a través del uso de los sentidos, comprendieran las diversas clases de tierra y sus papel dentro del equilibrio de la naturaleza, también dio espacio a la reflexión en torno a la contaminación, el desgaste de los suelos y su trascendencia a nivel económico, social y cultural de la tierra en comunidades rurales.

\section{Las imágenes de los recuerdos}

\section{Ingredientes}

- 10 fotos de lugares que la comunidad considere importantes

- Computador y videobeam

- Excesivas cantidades de creatividad

Porciones: cantidad suficiente para un grupo de personas, en este caso, las y los 28 estudiantes del grado 902.

\section{Forma de prepararse}

La esencia de este maravilloso platillo radica en que cada bocado debe evocar en cada comensal una repentina sucesión de recuerdos, en este caso y con la intención de generar un aprendizaje significativo alrededor de la memoria, se les aclaró a los y las estudiantes los conceptos de memoria histórico-colectiva y memoria individual, ya que la memoria de un pueblo se encuentra impregnada en los recuerdos colectivos que se tejen en torno a ciertos acontecimientos o lugares. Por lo tanto, el manjar que se quiere preparar cuenta con un alto contenido de percepciones individuales y colectivas que consolidan elementos de la tradición cultural de un lugar, en este caso de Sotaquirá.
En primer lugar, debes elegir concienzudamente los lugares que tengan mayor representación y trascendencia en la comunidad, por ejemplo la plaza del pueblo, el cementerio, algunos caminos, etc. Posteriormente, las presentarás al grupo de estudiantes para que cada cual escriba qué sensaciones o recuerdos personales y grupales le trae ese lugar. Teniendo esta mezcla lista, cada comensal agregará una pizca de su porción individual para colectivizarla en un relato socializado.

\section{Resultados}

A lo largo de la cocción, puede que se presenten manifestaciones de afecto o nostalgia entre los participantes, pero lo más probable es que los recuerdos que evocan las imágenes sean comunes. Así fue durante la aplicación de esta actividad, que sirvió para ejercitar la memoria individual, suscitó espacios de remembranza colectiva, al superar el escenario individual y generar preguntas en torno al significado de estos lugares para la comunidad. Por eso, los comensales coincidieron en el valor de los juegos típicos, las leyendas que se tejen en torno al cementerio, las tradiciones equinas, entre otros aspectos.

Este ejercicio constituyó una herramienta para que los estudiantes dedujeran, a partir de sus experiencias individuales y colectivas, el valor de la memoria como elemento fundamental de la historia, entendida como un proceso dinámico en constante construcción y de la cual ellos/as hacen parte. De igual forma, se propició un espacio de reflexión en torno a la cultura y tradiciones de la comunidad local, con el fin de que cada uno/a se atreviera a repensar y reconocer su historia cotidiana, para posteriormente compararla con lo establecido por la historia oficial y académica.

\section{Creando mitos}

\section{Ingredientes}

- Pliegos de papel suficientes para la cantidad de participantes

- Una buena porción y mezcla de témperas, marcadores y colores

- Una larga y amañadora charla con los abuelos o mayores conocidos

- Excesivas cantidades de creatividad

Porciones: cantidad suficiente para personas, en este caso, los y las 28 estudiantes del grado 902 . 


\section{Forma de prepararse}

Para realizar esta receta es necesario dejar algunos ingredientes listos con días de anticipación, pues los aderezos dependen principalmente de que se tenga lista esta primera parte. En primer lugar, se procederá a entablar cortas pero gratificantes charlas con los abuelos o mayores de la casa, familiares o vecinos. Esta fase es la más complicada, pero tendrá fundamental impacto la sazón del plato. Lo complejo de este proceso radica en la falta de costumbre que se tiene en charlar con los abuelos, por parte de los profesores, pero, una vez iniciada la tarea, será más sencilla y gratificante en las siguientes oportunidades. Es preciso que, durante las conversaciones, se mencionen elementos relacionados con relatos, cuentos, historias, leyendas y mitos que se conozcan.

El secreto para que el plato alcance la consistencia esperada radica en que entre más charlas casuales se tengan con los abuelos, propios o ajenos, aumentarán las posibilidades de fortalecer las relaciones intergeneracionales, y estimular la reflexión sobre el valor de la tradición oral conservada por la gente mayor, aumentando las probabilidades de que los jóvenes mantengan vivas las diversas historias atesoradas por los mayores.

Una vez contemos con la sazón de los deliciosos relatos cargados de magia, espectros, espantos y encantos heredados a partir de la tradición oral, es preciso compartirlos con el resto de participantes, para analizar qué elementos hay en común en todas las historias. Después se procederá a confeccionar artesanalmente un relato propio basado en las historias obtenidas. Finalmente, se plasmarán en imágenes los relatos de los abuelos y de los jóvenes con el fin de otorgarle un mayor valor a la tradición oral heredada ancestralmente, como se evidencia en la figura 5.

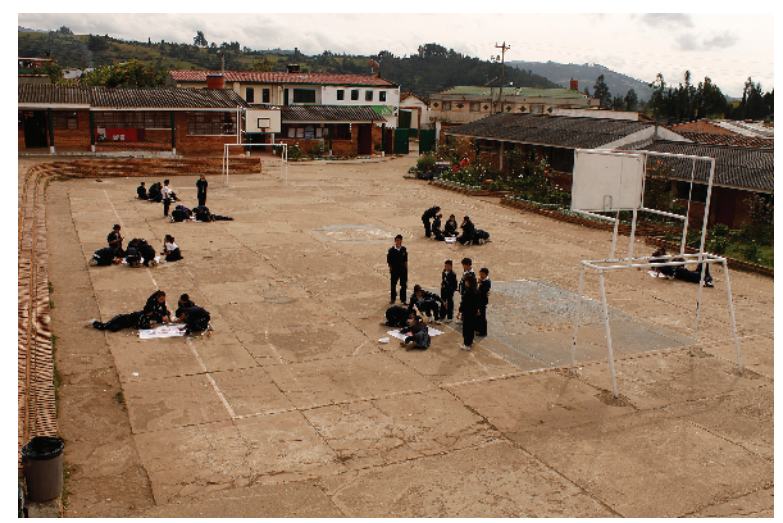

Figura 5. Estudiantes de COLPAVI Fuente: Juan David Corredor Robles.

\section{Resultados}

Este ejercicio nos dio a conocer la vigencia de la tradición oral, reflejada en las leyendas, cuentos populares, mitos y encantos que siguen vivos en el imaginario colectivo de los sotaquireños ancianos y jóvenes, pues muchos de los relatos obtenidos, a través de entrevistas $\mathrm{y}$ charlas con diferentes personas en el pueblo, coincidieron con las de los estudiantes. Al pedirles que elaboraran un relato propio, se les vinculó directamente con la responsabilidad social que tienen de perpetuar o modificar los relatos orales que han dado origen a todos los personajes mágicos que viven en sus historias fantásticas. Esto repercutió en sus percepciones respecto de la tradición oral, las charlas con los abuelos, el aprendizaje y las tradiciones culturales de su región.

De igual forma, el ejercicio contribuyó a fortalecer la escritura y la representación gráfica de los relatos, para propiciar espacios en los que las nuevas generaciones fortalezcan sus relaciones con los abuelos, a través del diálogo, y así otorgarle valor a los relatos fantásticos típicos en la región.

\section{Conclusiones}

La investigación que se sustenta en las experiencias mencionadas permitió suscitar espacios para la resignificación y reivindicación de la cultura sotaquireña, a partir de la educación de carácter popular, autónoma y consciente, en el marco de una pedagogía de la esperanza. De manera paralela al sistema positivista impuesto en la Institución Educativa Pablo vi, se contribuyó a que los estudiantes valoraran significativamente los elementos que hacen parte de su cultura regional y fortalecer los vínculos intergeneracionales.

Por otro lado, durante la aplicación de este trabajo de investigación se abrieron espacios para vincular las realidades sociales de carácter cultural del municipio de Sotaquirá con los procesos de enseñanza-aprendizaje generados al interior del sistema educativo formal. Este constituye el primer paso para flexibilizar la rigidez del proyecto educativo institucional, con miras a promover un proyecto educativo comunal.

\section{Referencias}

Ander-Egg, Ezequiel. El taller: una alternativa para la renovación pedagógica. Magisterio del Río de la Plata, 1991. Impreso. 
Buenaventura, Nicolás. La importancia de hablar mierda o los hilos invisibles del tejido social. Bogotá: Magisterio, 2001. Impreso.

Freire, Paulo. Cartas a quien pretende enseñar. México: Siglo Xxi, 1994. Impreso.

Ocampo, Javier. Historia y culturas populares los estudios regionales en Boyacá. Tunja: Nomos, 1989. Impreso.

El pueblo boyacense y su folclor. Tunja: Nomos, 1997. Impreso.
Pérez, Enrique, y José Sánchez. "La educación comunitaria: una concepción desde la pedagogía de la Esperanza de Paulo Freire". Revista Venezolana de Ciencias Sociales 9.2 (2005): 317-329. Impreso.

Rodríguez, Luis. Sotaquirá: poblado del soberano. Tunja: Jotamar, 1988. Impreso.

Warnier, Jean-Pierre. La mundialización de la cultura. Gedisa: Barcelona, 2002. Impreso. 